INTENSIVE JOURNAL

http://ojs.uniska-bjm.ac.id/index.php/EJB

E-ISSN 2620-4746

April 2021, Vol 4 No.1

\title{
CHALLENGES OF LEARNING ENGLISH THROUGH MOBILE DEVICES: EFL TEACHERS' PERSPECTIVES
}

\author{
Zainb Abbas Jawad \\ University of Diyala \\ Ahmedengineer730@yahoo.com
}

\begin{abstract}
There has been a growing interest in the use of mobile devices for mobile learning. There is a new branch of students in most schools nowadays who are easily connected to technology and innovative mobile devices. This study aims at investigating EFL teachers' perceptions concerning mobile devices usage for mobile learning purposes. It also aims at finding out whether or not there are any significant differences between male and female perceptions regarding this new type of learning. To achieve these aims, two instruments have been constructed by the researchers a questionnaire and an interview. The results are discussed and conclusions are drawn at the end of the study.
\end{abstract}

Key words: mobile devices, mobile learning, perceptions, mobile applications.

\section{INTRODUCTION}

The recent years have witnessed a rapid improvement of the existing setting in education by the evolution of technology. The broad use of mobile technologies as mobile phones (smart phones) and tablets'pDA have changed the classical academic environment to mobile learning. Evans (2008) \& Wu etal (2012) state that mobile devices can offer chances to support and enhance teaching and learning. Yang (2010) mentions that the integration of personal mobile devices of students in to the learning situation may change the whole learning process more to students.

Mobile devices are great means for both communication and education and they both needed and used in EFL learning environments. They are widely used by

Intensive Journal, Vol. 4(1), 2021 
most students because of their accessibility and mobility .Mobile learning is ,then , a new learning method in which the learners use their personal mobile devices to learn .They unified all the qualities of modern teaching, computer network technology ,mobile communication and multimedia technology. Wagner (2005) asserts that mobile learning supports the accessible learning experiences and the collaborative learning for both the students and teachers which are integrated anywhere and anytime beyond the classroom. On the other hand, Dayu and Haura (2016) focus on the idea that the use of video recording is a promising way of training teachers and students-teachers which is also one way of the use of mobile devices.

Depending on the researchers' long experiences in teaching English ,she noticed that most Iraqi teachers face great difficulties or challenges in teaching the English language .They lack the effective means for transferring the information provided by the prescribed textbooks of the English language for their students in an effective way as the most methods of teaching are traditional, inadequate and ineffective for motivating students to learn the English language. This comes in agreement with Al-Obaydi (2020) who mentioned that English teachers prefer making balance between virtual learning and face to face learning. So, this study has tackled to investigate teachers perspectives concerning a new trend of learning, i.e, mobile learning in which the students use their personal mobile devices to learn English language. This study is then an attempt to provide answers to the following questions:

1- What are EFL teachers' perceptions concerning mobile learning through using mobile devices?

2- Are there any significant differences between male and female EFL teachers regarding this new trend of learning?

\section{LITERATURE REVIEW}

Mobile learning is a new learning method in which the learners or the students use their own mobile devices as smart phones ,tablet ,iPod ,PDA ,etc. to learn English language .They unified all qualities of modern teaching as simplicity, affordability ,mobility, functionality, easiness of movement ,sharing information instantly and economic cost benefits .Rezaei ,etal(2013) present another definition of mobile learning which is a modern learning method in which the users can the use mobile platform to learn .It syncretizes all qualities of modern education ,computer network technology, mobile communications technology and multimedia

Intensive Journal, Vol. 4(1), 2021 
technology .It is also defined by Quinn(2000) as the interchange between mobile computing and the application of small, wireless and portable computing and communication devices, and e-learning. It is also learning that takes place with help of mobile devices (Attewei,2005).

\section{Types of Mobile Devices}

The common mobile computing devices and their features are presented below by Corbeil and Valdes (2017) in terms of their relevance to mobile learning. All these devices can be used actively in EFL teaching environments.

\section{1-I pod}

It is a potable media player that permits the user to download podcast, music, videos and audio books. Students can thus download audio and video lectures, readbooks, share information, provide visual direction and interface with the iPod through a microphone.

\section{2-PDA (Personal Digital Assistance)}

It includes a good combination of digital storage with internet access,computing power .It supports interactive and group learning .It also enables those who use it to access email and web content and play video and audio files .It can be regarded as a good choice because it integrates communication means.

\section{3-Smart Phones}

It incorporates telephone features with camera ,PDA and MP3 player .It supports internet access .So the users can download video or audio lectures ,flash movies edit text documents .It integrates too many options and features in one portable device.

\section{4-Laptop or Tablet Pc.}

It is the most functional of all the mobile devices and it has all the characteristics of a workstation Pc. It comes with the network support for Bluetooth, Wi-Fi Tablet Pc integrates hand writing recognition, voice to text conversation for input .Harmer(2010:p,191) asserts that some teachers prefer using tablet computer to laptop, because "they are easier to carry than laptop, they switch on and off more quickly than computers, students can carry them around in the lessons and share them easily in pair work task and they can be easily be passed from hand to hand" .Mobile devices can provide immediate feedback and availability of information and are thus valuable methods for learning.(Frago etal,2011)

Intensive Journal, Vol. 4(1), 2021 


\section{Importance of Mobile Devices}

Harmer (2010: $p$,191) asserts that mobile devices are very useful in education as life .He says that "some teachers get their students to use their mobile phone camera to take pictures which are difficult to interpret.The other students have to try to guess what they are ".

Mobile devices have the advantages to be used by many students to learn with apps "applications " as Harmer (ibid) mentions that "they are easier to use than many internet websites .Because the students only use one app at a time ,they are less likely to go to other internet site such as face book ,orkut, etc." He (2010:191) also highlights the importance of the apps saying "many apps have interactive tool. Students can communicate with each other They can make audio or video recordings and send them straight to internet sites." Rezaei etal (2013:20) mention another advantage of mobile learning saying that "the main advantage of mobile learning is its easy access at all times and being portable".

\section{Donalson (2011)}

The aim of this study is to examine the determinants of behavioral intention to use mobile learning by community college students and to investigate if there is any age or gender differences in the acceptance of mobile learning .The results indicated that performance expectancy, social influence perceived playfulness of learning and voluntariness of use are all significant determinants of behavioral intention to use mobile learning.

\section{Rezaei et al (2013)}

The objective of this study is to investigate the performance of the intermediate level English students before and after using mobile applications. Data collection was based on the before and after study design and on the questionnaire designed by the researchers. The results indicated that there was a positive change in the performance of the learners. The analysis of the questionnaire indicated that using mobile applications helped in maximizing the learning of vocabulary, class participations and confidence. They indicated that students had positive attitudes towards the use of multimedia in education.

\section{Lee (2014)}

The aim of this study is to determine EFL student differences in vocabulary learning based on the use of mobile devices instead of the traditional methods. This study used a mixed -method design using both quantitative and qualitative

Intensive Journal, Vol. 4(1), 2021 
methodologies and a pretest - posttest experimental design. The study results indicate that learning from mobile devices enhances learning.

\section{RESEARCH METHODS}

To achieve the aims of this study, sixty English language teachers where chosen randomly from the preparatory schools in Baghdad Al Russafa district to represent the sample of this study. Two instruments have been constructed by the researcher. A questionnaire and an interview. Bachman \&Palmer (1996: p, 243) assert that a questionnaire is "a rating scale which elicits responses to specific questions in the form of scaled, quantifiable data which can be subjected to powerful statistical analysis". It is worth mentioning that most items of this questionnaire has been elicited from the open -interview that the researcher has made with some English language teachers concerning the extent which they support or not the use of mobile devices for mobile learning .Some items are also collected on the basis of the previous studies on the same topic.

The questionnaire consists of (15) items which represents negative and positive opinions regarding the use of mobile devices for mobile learning. These items are supposed to elicit teachers perceptions by the three rating scales: 1- I agree 2- I partially agree 3- I refuse Likert scale is a technique to measure a person reaction to something or to show how strongly agree or disagree with the items of the questionnaire (Longman Dictionary of language Teaching \&Applied Linguistics, $\mathrm{P}$ $25 \& 213$ ). To ensure face validity of the items of the questionnaire, they have been exposed to a jury of experts in the field of methodology. Accordingly, some items have modified and other have excluded. Table (1) represents the final version of the questionnaire.

After ensuring the face validity of the items of the questionnaire, they have been exposed to the sample of the study which are (60) English language teachers from Baghdad. The researcher has used split -half method for calculating the reliability of the questionnaire. It is found that the correlation between the two halves of the scores i.e, even number items of the questionnaire and the odd ones ,is (0.81)for correlation purposes, Spearman-Brown coefficient is used and it yields( 0.88 ) which is considered acceptable. The final version of the questionnaire was given to the teachers at the beginning of January 2021 .The teachers were asked to reflect their opinions on the questionnaire concerning the three dimensions of the scale then the researcher has utilized the teachers responses.

\section{FINDINGS}

To provide answer to the first question of this study which is (what are the English language teachers perceptions or opinions concerning using mobile devices for language

Intensive Journal, Vol. 4(1), 2021 
learning?), the responses of the teachers were investigated by calculating the theoretical mean formula and the mean and by using the weighted mean. The mean score of the subjects was (44) compared with the theoretical mean (24). This result means that the mean is higher than the theoretical mean. This indicates that Iraqi English language teachers have positive tendencies on using mobile devices for mobile learning.

Table (1) Weighted Mean of the Questionnaire Items.

\begin{tabular}{|c|c|c|c|c|}
\hline Item no. & I agree & I partially agree & I refuse & Weighted Mean \\
\hline $1-$ & 59 & 1 & 0 & $0 \%$ \\
\hline $2-$ & 20 & 10 & 30 & $50 \%$ \\
\hline $3-$ & 58 & 2 & 0 & $0 \%$ \\
\hline $4-$ & 48 & 10 & 2 & $3 \%$ \\
\hline $5-$ & 30 & 3 & 27 & $45 \%$ \\
\hline $6-$ & 50 & 5 & 5 & $7 \%$ \\
\hline $7-$ & 20 & 10 & 30 & $50 \%$ \\
\hline $8-$ & 50 & 5 & 5 & $7 \%$ \\
\hline $9-$ & 48 & 10 & 2 & $3 \%$ \\
\hline $10-$ & 40 & 5 & 15 & $25 \%$ \\
\hline $11-$ & 30 & 3 & 27 & $45 \%$ \\
\hline $12-$ & 48 & 10 & 2 & $3 \%$ \\
\hline $13-$ & 58 & 2 & 0 & $\% 0$ \\
\hline $14-$ & 48 & 10 & 2 & $3 \%$ \\
\hline $15-$ & 48 & 10 & 2 & $3 \%$ \\
\hline
\end{tabular}

After presenting teacher opinions concerning using mobile devices for mobile learning, the weighted mean (50) was considered as an item that fail to gain positive opinion from teachers .Therefore, three items were gained negative attitude from teachers .They are presented as follows:

1- Item (2) which reads " Mobile learning environment decreases the affective obstacles or inhibitors by motivating students to be more active and less shy. "gains the most negative opinion from teachers. It got a weighted mean $(50 \%)$.

2-Item number (11) which reads " Learning from textbook is more efficient than mobile learning. "also gains negative opinion from teachers. It got a weighted mean $(45 \%)$.

3- Item number (5) which reads " Mobile learning is most beneficial when it offers students something, they can't obtain from in class communicative activity "gains negative opinion from teachers. It got a weighted mean (45\%).

Intensive Journal, Vol. 4(1), 2021 
For the purpose of providing answer to the second question of this study, the researcher has used $t$-test formula for two independent samples (male and female). The result illustrates that the computed $\mathrm{t}$ - value is 7,27 is higher than the tabulated $\mathrm{t}$ value 2 at 58 freedoms degree and 0.05 level of significance. This indicates that there are differences of statistical significance between male and female teachers' perceptions in favor of female teachers.

Table 2 Results of the Second Question

\begin{tabular}{|c|c|c|c|c|c|c|}
\hline \multirow[t]{2}{*}{ Gender } & \multirow[t]{2}{*}{ Number } & \multirow[t]{2}{*}{ Sd } & \multirow[t]{2}{*}{ Mean } & \multicolumn{2}{|c|}{ T.Value } & \multirow{2}{*}{$\begin{array}{l}\text { Level of } \\
\text { significance } \\
0.05\end{array}$} \\
\hline & & & & calculated & tabulated & \\
\hline Female & 30 & 3.04 & 23.7 & 7.72 & 2 & significant \\
\hline Male & 30 & 3.27 & 17.8 & & & significant \\
\hline
\end{tabular}

The results of the present study show that most Iraqi teachers of the English language have positive opinions concerning learning through using mobile devices. This reflects their need to change the traditional methods of teaching English language and look for alternatives means and innovations in the field of language instruction. The result of the second question of the study indicates that female teachers have more positive perceptions regarding mobile learning than male teachers due to their nature of being fond of innovation and change.

\section{CONCLUSION}

It should be noted that the findings of the current study comes in a accordance with Rezaei 'etal (2013) study which indicates that the students of the inter mediate level have positive opinions regarding the use of mobile application .It also comes in line with Lee's ( 2014 ) study which indicates that learning from mobile devices enhances students' learning when used independently and when combined with a teacher's instruction. It can be concluded that Iraqi teachers of English language have positive opinions and perceptions concerning the use of mobile devices for language learning .This means that Iraqi English language teachers look for a change in the traditional methods for learning the English language .It indicates that they are being quick to embrace new technologies regarding language learning. It can also

Intensive Journal, Vol. 4(1), 2021 
conclude that using mobile devices for mobile learning and application increases student's motivation to learn English language and can create variety and excitement. It can also improve their academic performance. It is worth mentioning that the results of this study come in agreement with Al-Obaydi and Jawad (2020) study who assert the positive opinions of teachers concerning the role of using mobile media and especially the personal learning networks in facilitating teachers' reflective practices.

\section{REFERENCES}

Al-Obaydi, L. H. (2020). Using Virtual Learning Environment as a Medium of Instruction in EFL Context: College Teachers' Attitudes. INTENSIVE JOURNAL. 3(2) http://ojs.uniska-bjm.ac.id/index.php/EJB E-ISSN 2620-4746

Al-Obaydi, L. H. and Jawad, Z. A. (2020). Personal Learning Networks as an Aid to Promote Reflective Practice by EFL Teachers. Diyala Journal. 83(2).

Attewell, J. "Mobile Learning Reaching hard -to- reach learners and bridging the digital devices" in G.chiazees

Dayu, A. T. \& Haura, R. (2016). Video Recording Mobile Phone Camera of Micro Teaching Subject in Teaching Skills of Students Teacher: The Case of Students Teacher Education in Islamic Kalimantan University MAB Banjarmasin. ICTTE. 1(1)

M. Allegra,A. Chifair,S,ottaviano Ed, "Methods and Technologies for learning ."Southampton WJt press,2005,pp..61-365.

Backman,Lyle and Adrain.S.Palm(1996) ."Language Testing in Practice. Oxford:Oup.

Corbeil,J.R. and Valdes ,M.E. "Are you ready for Mobile Learning".Educause Quartely,vo 1.30,2007,pp 51-58.

Donakan.Robin (2011) ."Student Acceptance of Mobile Learning Thesis.

Evans.C.(2008). "The Effectiveness of Mobile Learning in the form of Prodcast revision lectures in higher education computers.50 (2)421 -498.

Fraga,L.Harman,J.Wood,K\&Buckelew-Martin,E(2011)."Digital word walls and vocabulary learning . The use of ipod to Facilitate Vocabulary Instruction with ESL Students". Journal of the Research center for Educational Technonlogy".7(2).

Harmer,Jeremy.(2012)." Teacher Knowledge .Pearson: Winner.

Intensive Journal, Vol. 4(1), 2021 
Jeng, Y.L.,Wu, T.T,Huang,Y,M,Tan,Q\&Yang,S.(2010)."The add-on impact of mobile Application in learning Strategies .A review study .Journal of Educational Technology\&Society,13(3) 3-11.

Lee,Piyu(2014)."Are Mobile Devices more useful than conventional Means as Tools for learning vocabulary" .IEEE 8 th International Symposium on Embedded Multicore /Manycore Socs.

Pally,Marcia,(2000)"Sustained Content Teaching in Academic ESL/EFL. A practical Approach. New York :Houghton Mifflin company.

Quinn,C.,M. "Learning :Mobile Wireless ,In-Your-Pocket -Learning .Line zine ,full(2000).

Rezaei, A,Mai ,N and Pesaranghder A.(2013)."Effectiveness of using English vocabulary mobile Applications on Esl's Learning Performance." International conference on Informatics and Creative Multimedia.

Scrinver Jim (2011).Learning Teaching .The Essential Guide to Language Teaching .Macmilian.

Intensive Journal, Vol. 4(1), 2021 